This item was submitted to Loughborough's Research Repository by the author.

Items in Figshare are protected by copyright, with all rights reserved, unless otherwise indicated.

\title{
Redesigning the Indian food security system through e-governance: the case of Kerala
}

PLEASE CITE THE PUBLISHED VERSION

http://dx.doi.org/10.1016/j.worlddev.2014.10.014

PUBLISHER

(C) Elsevier

VERSION

AM (Accepted Manuscript)

\section{PUBLISHER STATEMENT}

This work is made available according to the conditions of the Creative Commons Attribution-NonCommercialNoDerivatives 4.0 International (CC BY-NC-ND 4.0) licence. Full details of this licence are available at: https://creativecommons.org/licenses/by-nc-nd/4.0/

\section{LICENCE}

CC BY-NC-ND 4.0

\section{REPOSITORY RECORD}

Masiero, Silvia. 2019. "Redesigning the Indian Food Security System Through E-governance: The Case of Kerala". figshare. https://hdl.handle.net/2134/22860. 


\title{
Redesigning the Indian Food Security System through E-Governance: The Case of Kerala
}

\author{
Silvia Masiero \\ LSE Fellow, Department of International Development \\ London School of Economics and Political Science \\ Houghton Street \\ London WC2A 2AE \\ s.masiero@lse.ac.uk
}

\begin{abstract}
The link between e-governance and development has been widely leveraged for policy formulation in India, however, little is known about its application to food security. This paper fills the gap with a study of Kerala, where the Public Distribution System (PDS), the main national food security programme, has been digitalized in its main functions. Findings reveal that the digital programme has been purposefully devised to combat the problem of diversion ("rice mafia”) of PDS goods to the market: however, issues of partial coverage and mistargeting remain. Lessons are drawn for other states computerizing the PDS and their social safety nets.
\end{abstract}

Keywords: Asia; India; Kerala; PDS; food security; e-governance

\section{INTRODUCTION}

Over the last decades, a rich body of literature has been built on the link between e-governance and development. At the theoretical level, information and communication technologies (ICTs) are viewed as carriers of efficiency and accountability, so that e-governance has come to be seen as "the digital route to good governance” (Heeks, 2001). The use of new technologies enables removal of discretional power from street-level bureaucrats, resulting in higher transparency of administrative processes (Bovens \& Zouridis, 2002): these considerations have been widely accepted in India, where the National E-Government Plan provides directives to improve governance through ICTs. Recently, 
new technologies have been highly used by Indian local governments, in order to improve their services to citizens (Bhatnagar, 2004; Bhatia, Bhatnagar, \& Tominaga, 2009; Madon, 2009) and to increase effectiveness of the social safety nets through which the country's poor are taken care of (Bussell, 2012; Pritchard, Rammohan, Sekher, Parasuraman, \& Choithani, 2013).

The theme of e-governance usage in social safety nets is to be observed, in contemporary India, with particular reference to the food security system, which is a central domain of the nation's anti-poverty strategy. India, notwithstanding an economic growth that has resulted in poverty reduction over time, ${ }^{1}$ is still facing a serious problem of widespread malnutrition: in spite of the redistributive food policies undertaken through the years, $40 \%$ of women and children are still undernourished (Sen \& Himanshu, 2011), and the nation ranks 105 out of 120 in the Global Hunger Index developed by IFPRI for $2013 .{ }^{2}$ The fact that malnutrition perpetuates the vicious circle of poverty is well-established in the literature (Pathak \& Singh, 2011), and ensuring food access to the poor remains a priority for India today: the main mechanism for facing the problem is the Public Distribution System (PDS), a food security programme that allows purchasing first-necessity goods at subsidized prices. Recently reformed by the National Food Security Act (NFSA) passed by the Lok Sabha on August 26, 2013, the programme has been long based on food subsidies targeted to households living below state-specific poverty lines.

The PDS is the biggest food subsidy system in India today. ${ }^{3}$ It is, for how it has been constructed, the main national programme to improve nutrition for the poor: the use of digital technologies in this scheme is therefore extremely relevant, as it relates e-governance to the most important mechanism of food security in the nation. Implementation of ICT-based solutions in the PDS is a responsibility of the state governments, and it is therefore important, to extract useful lessons at the all-India level, to examine the experiences of those states that have first engaged in this. Kerala has been one of the pioneers in this process, starting as early as 2001 with digitization of PDS user data. This paper, based on an in-depth case study of the Kerala PDS, focuses on how e-governance adoption, rather than just enhancing the effectiveness of existing processes, enables deep anti-leakage transformations in the very nature of the food security system. 
The paper, in this respect, plays both a descriptive and a normative function. From a descriptive point of view, I find that technology has been designed, and enacted in specific ways, in order to embody the state government's fight against the phenomenon (known as "rice mafia") due to which PDS commodities are diverted to the market for profit. By doing so, technology does not simply improve existing food security mechanisms, as standard programs of end-to-end computerization would do: rather, in the case of Kerala, it introduces new means to detect and prevent leakage, and is therefore instrumental in reconstructing the system through a novel accountability structure.

And still, I find that this process does not happen without problems. In the newly computerized PDS, one phase of the supply chain (constituted by sales of goods by fair-price vendors, known as ration dealers) is monitored more strongly than the previous ones: this lowers the potential of systems' transformation, as it limits the scope of ICT-based monitoring. Furthermore, the root cause of diversion, identified with the perverse consequences of a shift to a targeted PDS, has remained unchanged in spite of digital transformation. From a normative point of view, I draw key lessons from the case of Kerala: these are in terms of seeking holistic monitoring across programme's phases, and designing ICT-based interventions to target the root causes of problems (in this case, leakage from the PDS) rather than just their tangible effects.

The paper is organized as follows. Section 2 describes the Indian food security system, with a focus on the two main problems (exclusion errors and diversion to the market) that affect it, and provides a rationale to study the efforts towards computerization at the state level. Section 3 focuses on the case of Kerala, observing that e-governance has been introduced through digitalization of the main existing functions of the PDS. Section 4 observes that implementation goes beyond this, and takes the role of a direct mechanism to combat the diversion of PDS commodities: however, section 5 observes the issues emerging in this process, as technology, focusing on the final levels of the supply chain, targets the effects of the rice mafia, but not the root cause behind it. Section 6 concludes, with lessons for the other Indian states undertaking the same process. 


\section{THE INDIAN PUBLIC DISTRIBUTION SYSTEM}

Since national independence, social safety nets have played a major role in India's development strategy. As observed by Corbridge \& Harriss (2000), high reliance on anti-poverty schemes reflects J. Nehru's vision of independent India, which conceived protection of the poor as an integral part of development: this was structured, throughout national history, in the form of multiple interventions in favour of the poor and vulnerable. Social safety schemes, devised through the Central Government and implemented at the state level, are therefore at the core of India's development model. Food security, and the social schemes designed in order to ensure it, constitute one of the main dimensions of the vision of development implicit in this.

The first food security mechanisms in India were devised in pre-independence times. Before 1939, when rationing was introduced in Bombay as an emergency measure, colonial India lacked a regional food policy: dependence on foreign imports of foodgrains was high, and entitlement failures, combined with food deficits, caused between 1.5 and 3 million casualties in the 1942-1943 Bengali famine alone (Mooij, 1998, pp. 79-81). In this situation, a food department was created, to make purchases of foodgrains from private producers in surplus provinces, and allocate these to deficit provinces, where they would be sold at below market prices. This structure, initially conceived as an emergency measure, was maintained as India became independent, even though the first years were characterized by an inconsistent food policy (Mooij, 1998, pp. 81-82).

In 1965, the food security system formally took the shape of the PDS, with the creation of the Food Corporation of India (FCI). The FCI is the organization responsible for making the PDS work: it purchases food commodities (primarily rice, wheat, and sugar) and non-food items (mainly oil, kerosene, and cloth) from private producers, and distributes them at subsidized rates through a network of fair-price shops (FPS), also known as ration shops, throughout the nation. The establishment of the FCI was the key measure in institutionalizing the PDS as the main food security 
mechanism in India: in its initial formulation, the PDS was universal, in the sense that all beneficiaries were entitled to equal subsidies. From 1965 to 1990, the amount of foodgrains dealt with by the FCI increased from 10 to more than 18 million tonnes, and the number of ration shops grew to over 350000 (Mooij, 1998, p. 86): the expansion of the system enhanced its presence on the territory, improving poorer people’s capabilities to "see the state" in their daily lives (Corbridge, Srivastava, Williams, \& Véron, 2005).

[Figure 1 here]

Figure 1 provides a diagrammatic representation of the PDS supply chain. This is articulated along three phases: first, the commodities procured by the FCI and private producers, collected in storing spaces referred to as suppliers' godowns, are redistributed through wholesale points - Authorized Wholesale Dealers (AWDs) - throughout the nation. Second, commodities stored in AWDs are lifted by Authorized Retail Dealers (ARDs), the owners of the fair-price shops to whom goods are allocated on the basis of theoretical requirement - namely, of the number of households registered with each of them. ${ }^{4}$ Third, beneficiaries lift PDS goods from ration shops: each beneficiary household is entitled to a monthly quota, which can be collected at subsidized prices once the ration dealer has lifted his allotment. Entitlements to subsidized goods, which used to be universally equal, have changed as a result to the Central Government’s move to a targeted system in 1997.

In the early 1990s, indeed, the universal distribution system started receiving severe critiques under the fiscal profile. That was because, as the Central Government's reliance on the PDS for food security increased, the size of subsidy grew as well, from $0.04 \%$ of the GDP in $1970-71$ to $0.5 \%$ in 1990-91 (Ahluwalia, 1993). Both scholars and donors expressed serious concerns about such a substantial cost, faced in the middle of a severe fiscal crisis: several studies, at that time, pointed to the leakage to the non-poor, and consequent inefficiency, that the universal system entailed (Parikh, 1994; Radhakrishna \& Subbarao, 1997). What emerged from these studies was the presence of a 
minimum transfer to poorer people, achieved at an exorbitant fiscal cost: the suggested solution consisted in the introduction of a targeting mechanism, for leakage to the non-poor to be minimized.

Hence, as a consequence of the Structural Adjustment Programme started in 1991, a radical change was introduced in the PDS. In June 1997, the system moved from a universal to a targeted structure: PDS subsidy, which was initially equal for all citizens, became targeted to households identified as below-poverty-line (BPL), on the basis of poverty estimates by the Planning Commission. In 2000, one further measure was adopted in this respect, concerning the poorest of the poor: these households were included into a specific scheme, known as Antiyodaya Anna Yojana (AAY), which makes them subjected to even higher subsidies. Planning Commission estimates are conducted according to statespecific poverty lines: in the targeted PDS, subsidy is reserved to the BPL and AAY (except for a small component, which remains available to households above the poverty line), and allocation of goods by the FCI is based on relative poverty incidence in all states. ${ }^{5}$

The positive impact of these measures lies in the fact that targeting does, in effect, reduce subsidy expenditure (Umali-Deininger \& Deininger, 2001), and the targeted PDS has actually resulted in a positive contribution to nutrition, though this is found to be small in size (Kochar, 2005). Even so, data on the transfer determined by the targeted system are problematic: this transfer seems, consistently across studies, to be meagre, to the point that the system has been identified as a major failure by eminent scholars (Jha, Gaiha, Pandey, \& Kaicker, 2013; Svedberg, 2012; Sen \& Himanshu, 2011). These studies, while recommending diverse measures to improve food security, share one common denominator: they recognize that the targeted system has failed to meet its objectives, and that food security, in the current system design, is factually not guaranteed to the Indian poor.

Why has it been so? The failure of targeting was determined primarily by two coexisting problems, which undermined the system's functioning through intertwined mechanisms. The first problem is known as a matter of exclusion errors: the move from a universal to a targeted system, determining the exclusion of a large share of beneficiaries, has resulted in many needful households to be denied 
access to the PDS. Studies around exclusion errors identify two main reasons for them: first, the current method for poverty status determination - based on the scoring of 13 different criteria - is found to be prone to arbitrariness, which leads to the exclusion of genuinely poor households (Drèze \& Khera, 2010, p. 55). Secondly, issues are found with respect to poverty line definition, which is based on relatively low calorie norms - which leads to the exclusion of households at severe risk of malnutrition (Swaminathan, 2010).

In effect, data on exclusion vs. inclusion of households in the targeted PDS do reveal a potentially preoccupying situation. As illustrated by Swaminathan (2008, p. 16), households classified as BPL or AAY, at the all-India level, are just $29.5 \%$ of the total: this means that, in a nation still highly suffering from hunger and malnutrition, a large majority of households are excluded from food subsidies. ${ }^{6}$ This detrimental outcome results, to an extent paradoxically, from the very same targeting policy that was supposed to tailor the system specifically for the needs of the poor.

The second problem induced by targeting is related to dual prices, characterizing the same goods in the subsidized system vs. the free market. Dual prices determine an incentive to seek illicit profits, by diverting commodities from the PDS to the market: this practice is profoundly embedded in the targeted PDS, considered at the all-India level (Government of India, 2010). The incentive to diversion implicit in the system's design, coupled with frequently inadequate monitoring of state-level PDS supply chains, makes corruption a diffused dynamics in the PDS: unfortunately, corruption can be (as examined below) an attractive practice for PDS agents, especially as targeting, by narrowing the number of ration shop customers, has caused unviability of many FPS (Khera, 2011b).

A Committee appointed by the Supreme Court of India, studying the phenomenon of diversion, has referred to it as "rice mafia" (Justice Wadhwa Committee on Public Distribution System, 2010), a term that has entered common use with reference to corruption in the PDS. This phenomenon, whose likelihood increases where monitoring of PDS transactions is weak, is an issue that seriously hinders poorer people’s capabilities to access subsidized foodgrains. The struggle of the Central Government, 
to ensure food access to the poor through the PDS, largely coincides with a struggle against rice mafia: awareness of the programme has informed food policy debates, and has influenced directives for implementation at the state level. Still, according to estimates presented by UIDAI (2009), PDS commodities that every year do not reach intended beneficiaries amount to $57 \%$ of the total. ${ }^{7}$

It is in the context of the contemporary experience of the programme, affected as it is by exclusion errors and leakage, that the Central Government has openly endorsed the adoption of e-governance for states to enact the PDS. The discourse on computerization of social safety nets is gaining relevance in state-level policymaking, especially as a result of the diffusion of e-services throughout the public sphere: multiple experiences of digitalization, across the nation, have inspired narratives on the effects of ICTs on public service provision (Bhatnagar, 2004; Bhatia, Bhatnagar, \& Tominaga, 2009; Madon, 2009). More recent applications of this narrative have linked it to the improvement of social safety nets: computerization of social schemes has the power to transform the citizens' experience of these programmes, and ultimately of the state behind them (Bussell, 2012). Applied to the PDS, this causal argument is placed in the domain of food security: technology adoption has the primary rationale of enhancing people's capabilities to achieve their entitlements to subsidized food (Pritchard, Rammohan, Sekher, Parasuraman, \& Choithani, 2013).

On the one hand, the open codification of this effort is quite recent, as the PDS has been included in the National E-Governance Plan only in 2011. On the other hand, this coordinated effort has been anticipated by action from a few states, which have taken the initiative of computerization before then: now that explicit recommendations by the Central Government have been formulated, these states are in a good position to illustrate the implications of digitalization. Parlance on technology design for the PDS, ranging from supply chain monitoring (for example, through GIS devices placed on PDS trucks) to grassroots monitoring through websites or text messages, has gained strong relevance in the public discourse. The rationale mentioned above, linking ICTs to people's entitlements under the PDS, acts as a common denominator to these narratives. 
Over the last few years, several states (chiefly Chhattisgarh, Karnataka, and more recently Maharashtra, Delhi and Orissa) have embarked in programmes of digitalization of the PDS, as the National E-Governance Plan prescribes. However, the uniqueness of the Kerala experience lies in a combination of two points: first, its timing, which was one of the earliest in the nation (user data digitization started in 2001) and coincided, as noted below, with the reconstruction of the system after targeting. Second, its comprehensive nature, articulated (as of Section 3) in a modular structure that extends digitalization to all the four core functions of the PDS. Among other states, timing and comprehensiveness made the PDS in Kerala a prominent case to illuminate the dynamics of ICTbased food security.

In the current Indian context, two facts may result in structural changes to the programme: the first one is the diffusion of Aadhar, the nationwide system of biometric identification that states may integrate in the PDS (UIDAI, 2009). The second one is implied by approval of the NFSA, which will restructure the PDS towards a return to quasi-universality of the programme. ${ }^{8}$ These facts need to be considered when focusing on the PDS, and my study has been conducted, as a result, with regards to the dynamics of transformation (with specific reference to Aadhar, since the NFSA was approved quite recently, and at the moment of writing it has not yet affected the digital aspect of PDS implementation).

My research consists of a state-level case study, conducted in Kerala over two research visits of three and four months respectively, between November 2011 and September 2012. I have used a primarily qualitative method of data collection and analysis, working directly with the actors involved in computerization of the PDS: overall, 126 in-depth interviews have been conducted, predominantly with actors responsible for the design and use of the digital PDS (software developers, government officials, programme officers) and with final users of the programme (citizens of Kerala availing the system). As I worked with a research question informed by the link between e-governance and development, the focus of my study has been on the processes of change induced by technology: narrative analysis, one of the main tools for process research (Riessman, 2008), has therefore been the 
main method on which I have relied. As I followed the case study method (Yin, 2009), I have triangulated interview data with sources consisting of notes from participant observation, statistics on local programmes and their impact, press releases, and government documents regarding the PDS.

\section{KERALA: USING E-GOVERNANCE IN THE PDS}

Before 1997, Kerala was widely recognized as operating one of the best PDS programmes in India (Suryanarayana, 2001; Swaminathan, 2002; Suchitra, 2004). Under the universal system, PDS distribution catered to $97 \%$ of the state's population (George, 1979, p. 23), and the impact on beneficiaries' nutritional status was high and significant (Kumar, 1979). This was very relevant in a state whose food-deficit situation, per se, would put people's nutritional security in peril: Kerala depends on neighbouring states for $85 \%$ of its food requirements (Justice Wadhwa Committee on Public Distribution System, 2010), and this increases the importance of operating a well-functioning food security programme. The Keralite system, and the operational efficiency that characterized it, were based on the universality of PDS, and on its capability to serve the population in its quasientirety.

In a country where the transition to capitalism has occurred through a "passive revolution" (Chatterjee, 1986), the history of Kerala is sui generis, in that it has witnessed a social transition from below: the class agency of rural peasants was key to subverting feudal relations of production (Heller, 1995). Kerala's political history, characterized by strong popular participation, was instrumental in generating the current, atypical development outcomes: sustained public action led to high social development, but at the same time, the imperative of redistribution may have acted as an obstacle to economic growth (Véron, 2001). Since independence, the imperative of redistribution constituted a key pillar of Kerala politics, and this led governments to take the PDS very seriously: furthermore, starting from 1965, ration shops were supervised by People’s Food Committees, which would closely control the accountability of local retailers (Mooij, 1998). The combination of governmental care and people's participation was instrumental in the success of the universal distribution system. 
The 1997 shift had major consequences on Kerala. As a result of the new food policy, a previously well-functioning system was led to a factual collapse: as $25 \%$ of the population was identified as BPL by the Planning Commission, allocation of foodgrains to the state, in the targeted system, was reduced to less than $10 \%$ of the previous supply (Swaminathan, 2002, p. 51). The state government, reestimating poverty incidence, identified $42 \%$ of the population as BPL, and provided food subsidy to the additional households from the state budget: even so, the sudden drop in supply of subsidized commodities had severe negative implications on the state-level PDS, which started encountering diverse kinds of issues.

Problems faced by the newly targeted system affect both the demand and the supply side. First, targeting caused a massive drop in the demand for PDS goods: with the minimization of subsidy (see Table 1) for those above the poverty line (APL), the quasi-totality of these households opted out the PDS, and switched to the private market instead. The outcome of this process was, in turn, a substantial drop in purchases from the PDS at the state level, which went from 4.64 tonnes in 1997, to 1.71 in 2001 (Khera, 2011b). Second, the supply side managed by owners of fair-price shops (known as ration dealers) was severely hit as well: as a result of the drop in the customer base, FPS started becoming unviable and closing down, because purchases from them became insufficient to generate profits (Krishnakumar, 2000; Nair, 2000).

[Table 1 here $]^{9}$

One first consideration emerging from my data is that the computerization of the PDS, in the Kerala experience, is deeply embedded in this crisis context: the introduction of e-governance constitutes, indeed, a measure taken by the state government to revamp a system that was led to collapse. ${ }^{10}$ The digitalization of PDS operations, stemming from a proposal by the state government in the late 1990s, has been delegated to the National Informatics Centre (NIC), the main national enabler of e- 
governance services. In this task, NIC Kerala has been supervised by the Kerala State Information Technology Mission (KSITM), the agency responsible for the provision of e-governance services.

Computerization of the PDS was started in 2001, with the creation of a database of all users. This was the outcome of a state-wide data digitization project, in which delegated ward members went door to door to collect cardholder information: data entry was performed, at the district level, by members of Kudumbashree, a women's organization depending on the State Poverty Eradication Mission. Details so collected were then transferred into a central database, for the purpose of digitization of ration cards: a ration card is a household-based document that citizens need to access the PDS, as ration dealers are only allowed to sell them subsidized goods upon presentation of this document. As a result, details of all cardholders in the state can now be availed, verified, and modified upon request by staff at Taluk Supply Offices (TSOs), the administrative offices of the PDS.

The state-level database of PDS users constituted the basis for NIC Kerala to create a dedicated suite of software, which automatized the main tasks performed at the TSOs. This is known as Targeted, Efficient, Transparent Rationing and Allocation Public Distribution System (TETRAPDS): it is a programme that articulates the food security concept, as materialized through the PDS, into key functions, and dedicates a specific module to each of them. The software consists of four modules, whose functioning is detailed below.

Module 1, known as the Ration Card Management System (RCMS), is a workflow-based application for requesting ration cards, and for modifying existing ones as per citizens' requests. ${ }^{11}$ Its functioning is articulated as follows: once received through the registration counter, applications are verified by rationing inspectors, which then submit them to the local TSO for approval. Applications are normally performed through Akshaya centres, the telecentres (public-private Internet kiosks) located across the entire state territory. The function of this module is that of guaranteeing that PDS beneficiaries are actually enabled, through ownership of a ration card, to buy subsidized goods from the ration shops: 
at present, RCMS is being integrated with the Aadhar database, for citizens to purchase PDS goods simply by inserting their fingerprints into point-of-sale machines that are to be installed in FPS.

Module 2 is based on Allocation 2.0, an application for the allocation of subsidized commodities among the retail dealers located across the 14 districts of Kerala. Through Allocation 2.0, Taluk Supply Officers are enabled to ascertain the theoretical requirement of each ration dealer in their taluk (administrative area) of reference, and allocate PDS goods among them consequently. This application works in connection with the cardholders' database, which reveals the number of households registered with each ration dealer, and the quotas of commodities to which each of them is entitled on the basis of poverty status. Optimizing allocation is of paramount importance today, especially as targeting has significantly reduced the amount of PDS commodities available to Kerala.

Module 3 consists in an Inspection Monitoring System, and registers the outcomes of the controls conducted periodically by rationing inspectors, in the FPS of each taluk. Rationing inspectors have the task of performing controls on the main operations of the PDS: these include both the ration card management process, and the sales and registrations carried out by ration dealers. The Inspection Monitoring System is a database that registers, for each taluk, the inspections conducted, the irregularities detected, and the action taken in cases of illicit conduct. ${ }^{12}$ Due to widespread irregularities, and to the strong presence (reviewed below) of rice mafia on the territory of Kerala, these operations need to be closely and constantly supervised, and module 3 constitutes the digital embodiment of the monitoring function that food security entails.

Module 4 consists in a platform (WebPDS) for interaction of the Food and Civil Supply Department with PDS beneficiaries, which allows citizens to access portal services on the Internet. Through this portal, people can obtain information and perform tasks related to the PDS: they can apply for a new ration card, download forms to apply for benefit schemes, lodge complaints, and receive details on PDS commodities lifted at the state level. This module is the only one that does not have a back-end component at the Taluk Supply Offices, as it consists in a front-end interface with citizens. 
[Table 2 here]

Table 2 summarizes the key functions of TETRAPDS. What is most important, in this descriptive part of the paper, is the finalistic nature embedded in Kerala's use of e-governance: as noted, each module consists in the digital enactment of one function of food security under the PDS.

Studying the link between e-governance and food security implies observing two parallel domains of enquiry: first, there is a question on how technology is embedded in the PDS, answered above in terms of the computerization of key functions. A second question, and the one at the core of the study, is on why e-governance has taken this specific shape: this requires, beyond descriptive narratives, an analysis of the processes of developmental change enacted through technology. Below I use narratives from actors in the PDS to answer this question, through interpretation of the intertwining mechanisms of state politics and computerization.

\section{PURPOSEFUL DESIGN: COMBATING DIVERSION THROUGH ICTs}

Narratives at the government level reveal, in the first place, asymmetries in the adoption of TETRAPDS modules, which are not equally implemented in all TSOs. More specifically, RCMS is the key module in the programme, and the one that benefits from the strongest political investment: its application is reported to be operating in all TSOs, while this is not the case for modules on allocation and monitoring, whose rollout has not yet been completed. ${ }^{13}$ Instead, the front-end component of RCMS (the online ration card application) is highly utilized by citizens: it is, in effect, one of the services that are most frequently used at Akshaya centres. ${ }^{14}$

Incomplete implementation of modules on allocation and monitoring can be ascribed to two primary factors, which feature frequently in taluk staff's recounts. Firstly, awareness of the software is still partial - in several taluks, while government circulars about imminent computerization have been 
received, the shift to TETRAPDS has not yet been made, and staff members seem uncertain about whether and how this will take place. Secondly, PDS has operated on a non-computerized basis for four decades: deep entrenchment of the programme in the state's anti-poverty structure has led to crystallization of work routines, which, in the taluks that have actually adopted TETRAPDS, have been significantly altered by technology. Staff members, faced with the software for the first time, reported experiencing severe difficulties in terms of utilization, reinforced by the fact that training on TETRAPDS usage - while reportedly conducted across all taluks - was received by only a minority of the interviewed officers. ${ }^{15}$

Most importantly, it emerges that the programme at the core of computerization, rather than using RCMS per se, consists in its integration with Aadhar, the identification system devised and promoted by the Unique Identification Authority of India (UIDAI). Led by the ex-chairman of Infosys, Nandan Nilekani, Aadhar aims at providing unique identification to all Indian citizens, through a unique 12digit number and the registration of biometric details: enrolment of citizens, started in 2012, is being performed throughout the whole nation. The purposes of Aadhar relate to bureaucratic simplification, secure identification of citizens, and their equality before the government, stemming from the fact that a plethora of documents will be reduced to a single number, whose structure is equal for all. The current Kerala government is a strong political champion of Aadhar: as a result of its major efforts in promoting citizens' registration, the programme has reached impressive rates of adoption (at the moment of writing, more than $95 \%$ of the state population has enrolled for it).

Aadhar's importance, as a tool for reforming the PDS, emerges very clearly from governors' narratives. The purpose of its integration with RCMS is that of enabling biometric identification of customers, when they make purchases at the FPS: the Aadhar-enabled RCMS is currently under construction, and a trial has recently been conducted in six ration shops in Trivandrum district. The trial has been based on the use of point-of-sale machines, installed in the ration shops, which recognize Aadhar registered citizens on the basis of their fingerprints. The chief reason for constructing the system in this way is that one of the main problems, identified in the system by the 
Justice Wadhwa Committee on Public Distribution System (2010), is the high prevalence of bogus ration cards, utilized to divert goods outside the PDS to generate profits.

The reason for proliferation of bogus ration cards, as reported in government officers' narratives, needs closer examination. According to their recounts it is, indeed, not the citizens, but the ration dealers that engage more actively in the production of fake cards, to register non-existing users into their shops and simulate sales to them - and mask, by doing so, illegal transactions to the market. ${ }^{16}$ Procedures to obtain a ration card (and in particular, a BPL one, to which more substantial entitlements are attached) are rigorous in the state's law: and still, these are reported to be bypassed on a frequent basis, leading to illicit inclusion of non-entitled or "ghost" (non-existing) users in PDS provision. Computerization is to be seen, in the first place, as a response to this phenomenon, as it constitutes the primary means to ensure that only genuinely entitled users access the PDS.

Why would Aadhar be so relevant in reforming the PDS? This is explained by the operational change that it will induce in the food security programme, which is clarified by the functioning of the Aadharbased scheme. Once the trial phase is completed, and the system is scaled up to the whole state, pointof-sale machines should be implemented in all ration shops: as in the trial described above, people will use their biometric details, rather than a ration card, as a means to prove entitlement. In this way, identification procedures will be automatized, and the current means of identification (based on a barcode embedded in the ration card, and still easily bypassed) will be substituted by secure controls. ${ }^{17}$ At the same time, through point-of-sale machines, sales of PDS goods will be automatically traced, to ensure that these are directed to genuine PDS beneficiaries.

The heart of my analysis follows directly from this: the integration of Aadhar in the PDS, as depicted by governors' narratives, is being conducted for a specific purpose, which is that of creating an ad hoc instrument to combat the rice mafia on the territory of Kerala. This means that technology, rather than being designed to enact a generic notion of accountability, has been devised for a specific developmental purpose, that of preventing the illegal transactions that divert subsidized foodgrains 
away from the poor. Governors' narratives explore several aspects of e-governance as a tool to fight the rice mafia: there are, primarily, three mechanisms through which technology has become a physical embodiment of this purpose.

The first mechanism consists, as noted above, in the use of Aadhar to enable secure identification of PDS beneficiaries. This is a direct response to the problem of bogus ration cards, which are a key instrument of diversion, because they are largely used by ration dealers to mask their illegal transactions. In response, Aadhar guarantees secure identification through biometric details: therefore, as it is integrated with RCMS, the invention of non-existing customers becomes de facto impossible, as each transaction will need to correspond to a citizen registered in the Aadhar database.

The second mechanism, parallel to the first one, lies in Aadhar monitoring the offtake of goods, as it occurs at every transaction conducted at the ration shops. Beyond checking the identity of buyers, point-of-sale machines register the amount of commodities that are sold at every transaction: all operations are therefore registered in the database, and this leaves no room for ration dealers to invent sales that never occurred. In addition, the system allows to verify that sold quantities match those received by FPS after monthly allocation: in this way, ration dealers cannot pretend to be "running out” of PDS goods, in order to mask diversion to the private market. This mechanism has been designed ad hoc in order to identify and prevent this form of diversion. ${ }^{18}$

The third mechanism, acting on the demand side, lies in a prospective structural change that will come with Aadhar implementation, and consists in delinking ration shops from registered households. This will increase the accessibility of the system: in the present situation, dictated by the Kerala Rationing Order of 1966, every household is linked to one ration shop, and can buy PDS goods only from it. As a result, if customers realize that the ration dealer is misbehaving (most frequently, by pretending to be out of stock), there is no way to react: instead, Aadhar enables access to the system from all ration shops, as point-of-sale machines can recognize citizens in the state as a whole. This implies enabling citizens, for the first time, to directly opt out of ration dealers whose conduct is suspicious. ${ }^{19}$ 
These three mechanisms constitute the core of PDS digitalization. It is their combination that leads to my core argument: by determining secure identification, monitoring the offtake of goods, and enabling citizens to opt out of corrupted ration dealers, the digital PDS physically embodies the Kerala government's stance against the rice mafia. Through these mechanisms, technology goes beyond the descriptive aspect, reviewed above in terms of its four key functions: the form of egovernance that Kerala is promoting is one that identifies the core problem of food security, and devises a specific system in order to solve it. Technology acquires, by doing so, a political value, embedded in combating the issue that prevents poorer people from accessing the food security system.

Hence, the digital PDS in Kerala aims to be a means to liberate the PDS from the rice mafia. The process of translation of this objective into practice, though, does not occur without problems, and this leads me to focus on the actual reception of the digital PDS by the programme' beneficiaries.

\section{FROM DESIGN TO PRACTICE: PROBLEMS OF THE DIGITAL PDS}

At the moment of writing, programme implementation is still in a too early stage for the impact of the Aadhar-based PDS to be measured. TETRAPDS (in its current modular structure) has been operating for more than five years, and has been instrumental in automatizing the operations of TSOs: still, the Aadhar system is being integrated in it just now, and its trial has only affected a few ration shops in Trivandrum district. To estimate the extent to which this may reshape the food security system, statewide rollout will need to be completed: since an order of the Supreme Court of India (September 2013) forbids conditionality of social programmes to Aadhar registration, an alternative mechanism will have to be devised, for those PDS users who choose not to enrol in the Aadhar scheme.

Still, even at this early stage, a few problems emerge, and lead observers to doubt on whether Aadhar may be, per se, capable to lead the system's transformation. These issues belong to the macro-areas of supply chain management and causal mechanisms of diversion: their substance emerges strongly from 
actors' narratives, when broadening the focus from PDS policymakers to the ration dealers and users of the programme.

The first issue that emerges, in the current system design, lies in the lack of a mechanism of direct control on the PDS supply chain, which is not monitored at the level of FCI godowns and wholesale dealers. It is true, on the one hand, that TETRAPDS modules 2 and 3 focus respectively on the allocation of goods to the FPS, and on the monitoring of ration dealers' behaviour. Yet, module 3 only focuses on inspections in the ration shops, and does not provide any form of control on the supply chain through which goods are supplied to them. Second, these modules are underused in the TSOs at large, and there are instances in which they have not yet been implemented at all.

A potential explanation here is that, in the new digital PDS, the Aadhar technology will play the functions of modules 2 and 3, because it factually covers their tasks. Indeed, as noted above, Aadhar does not simply verify users' identity: it is, at the same time, a means for monitoring the offtake of goods from the ration shops, ensuring that these are supplied to real PDS users. Offtake records provide, over time, an account of the theoretical requirement of each ration dealer, and this substitutes the function of module 2: in parallel, point-of-sale machines ensure that transactions occur with genuine PDS beneficiaries, and this plays the inspective function of module 3. Therefore, Aadhar integration could be seen as a form of restructuring that makes these modules redundant.

The core of the problem lies, though, in the assumption implicit in the presently designed technology, in which Aadhar acquires the role of a proper monitoring device. To understand this, system design should be observed in its full picture: as a result of Aadhar's integration, ration dealers are controlled, and prevented from selling PDS commodities outside the system. This identifies ration shop owners as the one actor responsible for corruption, and monitors their behaviour to prevent this. Two questions need to be asked in this respect: is it correct to blame diversion primarily to ration dealers, and how suitable is the current mechanism to prevent them from engaging in illegal transactions? 
As far as the first question is concerned, a preliminary consideration needs to be made. The PDS supply chain is a long and complex one - commodities go through a plethora of passages, leading from the FCI godowns to AWDs at the district level, and reaching ARDs in each taluk before being sold to beneficiaries. It can be observed that, in theory, each level of the supply chain leaves room for diversion: still, TETRAPDS only monitors transactions in the ration shops, and no digital device is in place to check the operations happening beforehand.

Still, analysis of PDS users' narratives casts serious doubt on whether ration dealers may be the only, or even the principal, guilty part for the total amount of diversion from the system. Citizens, in their recounts of direct experience of the PDS, reveal something that did not emerge in interactions with policymakers: diversion is perceived, at the users' level, as occurring largely outside of the ration shops, and away from the current monitoring mechanisms. This means that corruption, as conceptualized in citizens' perception, does not interest solely the ration dealers, but a system of actors intertwined with the public and private sectors.

This assertion is articulated in two themes. First, monitoring mechanisms on ration dealers are into place at the community level too, as citizens' groups are actively organized and directly operating for this purpose. Community monitoring of ration dealers, started in the 1960s, continues in Kerala to the present day: this is perceived as a means to limit capability of these actors to deviate, as public vigil and civic awareness are still very strongly enacted in the state. Yet, community monitoring can only be exerted on actors that have a physical presence in towns and villages, which makes operations at the FCI godowns and AWDs exempted from this form of control. ${ }^{20}$

Second, the dynamics of corruption necessarily involve private actors coming from outside the PDS, as the proactive participation of business is vital for illegal trade networks to thrive. In fact, a rice mafia phenomenon could not exist without the involvement of private counterparts, which engage in purchasing PDS products and reselling them on black market networks. ${ }^{21}$ As per the awareness embedded in citizens' narratives, involvement of private actors is fundamental for corruption to take 
place: in identifying those responsible for diversion, these actors should be considered too, rather than adopting a system that focuses exclusively on ration dealers, as the Aadhar technology does. ${ }^{22}$

The first problem with the Aadhar-based PDS is, therefore, that it is designed to track transactions at the ration shop level, without any check on what happens before or outside the FPS. Yet another question needs to be asked in parallel, and it concerns the extent to which the Aadhar-based technology is suitable, in practice, for preventing the misbehaviour of ration dealers. To be sure, it needs to be observed that the point made by the state government, that ration shop businesses are profoundly affected by the corruption resulting from illegal transactions, is reflected by data on the offtake of PDS goods. In fact, according to the Government of India (2010: 239), estimated diversion amounts to $28 \%$ of wheat, $23 \%$ of rice, and $25 \%$ of sugar supplied through the PDS in Kerala. ${ }^{23}$

Citizens' narratives, triangulated with data on offtake, confirm the presence of this phenomenon, and its negative influence on poorer people’s capability to access subsidized food items. Despite the fact that ration dealers may not be the sole guilty part here, they still tend to be found in a complicit role: as reported by PDS customers, all too often below-poverty-line recipients go to the ration shops only to be turned down by the staff, who claims having "run out" of monthly quotas. ${ }^{24}$ This type of diversion, and the main mechanism (based on bogus ration cards) through which ration dealers mask illegal transactions on the market, is, at least on paper, effectively combated by Aadhar, which monitors the offtake of PDS goods exactly at the ration shop level.

And still the problem, which is not contemplated by the current technology design, may be elsewhere: the question here is, what is the root cause of corruption? Indeed, to effectively target an existing issue, a development measure needs to target its cause, not simply address its main effects and leave the problem's origin unchanged. Development measures that only target effects are likely to turn out into ineffective outcomes, because they do not stop the problem from replicating itself in new settings. 
Ration dealers' narratives, collected on the field, establish a close causal relation between the phenomenon of market diversion and its root cause. This reason is ascribed to the move to a targeted system: this has induced severe unviability into the FPS, taking away a large share of their customers and the financial sustainability that was previously assured. As noted above, this happened due to a system that, as a result of relatively low estimates of poverty incidence, classified the majority of Kerala households as APL: given the low subsidy to this status, these households have massively moved to the private market, leaving ration dealers with a weakened customers' base. Many ration dealers resorted to debt in response, and difficulties in repaying it caused a massive wave of suicides among FPS owners (Suchitra, 2004): those that did not close their shops have a strong incentive to diversion, which as of Khera (2011b) has become a requirement of economic survival for them.

The sad, but factual necessity of market diversion to survive strongly emerges from the narratives of actors in the PDS, including the Taluk Supply Officers themselves. Across the collected recounts, the point in time when conditions for the PDS have changed is very precise: it is to be found in 1997, the year when targeting measures were introduced by the Central Government. ${ }^{25}$ The loss of customers that followed for the FPS still conditions the basis of ration dealers' activity, and narratives cluster strongly around this point: carrying out a ration shop business, and preserving its viability, means indulging in a certain amount of exchanges with the private market. This is indeed not contemplated by the law, but it seems to be, de facto, the only way for ration dealers to maintain their shops. ${ }^{26}$

Back to the Aadhar-based PDS, the problem with technology design lies exactly here: the system does, indeed, control ration dealers' behaviour and detect illegal transactions, but it does not act on the root cause of the problem, namely the perverse consequences of targeting. With Aadhar, the invitation for FPS owners to comply with the law will be technologically enforced: but still, the system does not offer them an alternative, in terms of how to make a living without market diversion. In this way, technology comes across as both partial and mistargeted: partial, because it only targets the ration dealers and not the other actors in the supply chain, and mistargeted, as it addresses the effect of the problem and not its root cause. 
What could be done, on the other hand, to address the root cause of the problem? Given the nature of the issue, lying in factual unviability of the FPS under targeting, measures should be taken in order to allow ration dealers to increase their incomes without resorting to illegal sales. According to the Justice Wadhwa Committee on Public Distribution System (2010), the solution lies in giving them a higher commission on PDS goods, and allowing them concessions to sell more commodities rather than solely items subsidized under the PDS. An even more profound and desirable measure has been taken by the Lok Sabha, which passed the NFSA in August 2013: this act, which constitutes a strong move back in the direction of quasi-universality, has significant consequences in terms of reducing the incentive to corruption that came with the targeted system.

To recap, my analysis has revealed that, on the one hand, computerization of the PDS in Kerala is purposefully designed to combat the rice mafia. On the other hand, the problems detailed above cast serious doubts on the system's capability to play this function in an effective way. As argued below, deep rethinking is therefore required, for technology to be able to effectively ensure access to subsidized food for poorer people.

\section{LESSONS AND CONCLUSION}

The government of Kerala has computerized the PDS to combat the phenomenon of rice mafia, which prevents beneficiaries from accessing the subsidized food items that they are entitled to. The system has been devised specifically for this purpose, and combines a set of functions to track transactions at the ration shop level, while allowing beneficiaries to opt out of ration shops that engage in suspicious conduct. Still, problems are related to a technology design that identifies ration dealers as the main actor in diversion, and that focuses on the effect of the problem without tracing its root cause. As a result, the programme ends up suffering from limited coverage of the PDS supply chain, and from a mistargeted focus that limits its effectiveness in the long-term fight against corruption. 
Two main implications are drawn from this case, for the adoption and usage of e-governance mechanisms in the domain of food security. First, the idea that technology can act as a "carrier of policies” (Cordella \& Iannacci, 2010), for governments to use ICTs as means to put forward a propoor political agenda, may constitute an optimal basis for digitalizing food security programmes. In the case of Kerala, the core problem of the PDS is identified with the rice mafia phenomenon, due to which subsidized goods are diverted outside the system: technology is therefore devised as a problemsolving device, to prevent the illegal transactions that lie at the core of the issue. By doing so, technology is configured (not as a neutral instrument, but) as an embodiment of the political objective of preventing illegal networks from infiltrating the PDS.

A second lesson is that, at the same time, a well-designed technology is not per se sufficient to improve the effectiveness and accountability of food security programmes. For this to happen, technology needs to target the structural nodes of existing problems: incorrect assumptions, in this respect, lead to gaps between optimal design and practical capabilities of achieving better outcomes through ICTs. In the case examined here, the system treats the ration dealers as the only actor responsible for corruption, when the phenomenon is known to be endemically diffused across the whole supply chain. Furthermore, the system detects illegal transactions at the ration shops, but does not focus on the cause - FPS unviability induced by targeting - that induces ration dealers to indulge in this: as a result, it does not face the structural nodes of the issue, which constrains its capabilities of solving existing problems.

From the case of Kerala, lessons for other states computerizing the PDS can be derived. A potential caveat here is that findings on Kerala can hardly be seen as representative or replicable across India, as its levels of social development, compared to other states, may be significantly more conducive to successful computerization. On the one hand, it is true that Kerala's development model is sui generis, as well as the conditions that it creates for public reform. Yet there are, in my view, two major reasons for drawing India-wide lessons from this case: first, in part as a result of its favourable conditions, Kerala was able to computerize its PDS significantly earlier than other states, and is 
therefore in the position of illustrating the dynamics of digitalization through its own experience. Second, leakage constitutes one of the main causes of PDS ineffectiveness across India, and the choice of a technology that carries political purposes (while context may have facilitated it) deserves to be brought to the attention of states experiencing the same problem.

The core conclusion here is that technology, rather than simply automatizing the functioning of antipoverty mechanisms, can act as a means to reform, which substantially redesigns the nature of existing social safety nets. This is particularly relevant to the PDS, when observed in an all-India context: indeed, over the last years, the impact of PDS reform on the poverty gap index has become high and significant (Drèze \& Khera, 2013). Most importantly, this is true at the state level too: several states, particularly Chhattisgarh and Orissa, have experienced strong improvements in utilization of the system and reduction of leakage, and Bihar, historically known for severe drawbacks in implementation, is following on the same route (Himanshu, 2013). My study adds to these findings by stating that technology, constructed in a finalistic way, leads to enact a kind of reform that is capable of determining better outcomes in the system.

In turn, two lessons on technology design for the PDS (and for anti-poverty schemes at large) are built on this conclusion. The first one observes that, if diversion is found to be endemic across the PDS supply chain, then ICT-enabled monitoring needs to be holistic, rather than being focused solely on the transactions occurring in the ration shops. Monitoring needs, therefore, to be extended to the supply chain in its entirety: otherwise, opportunity for leakage remains high in the phases that do not involve the ration dealers. Technologies based on geographic information systems (GIS), devised to track the movement of goods from FCI godowns to AWDs - and then to ration shops in each taluk, may play a major role in this respect, because they extend control to those phases that Aadhar, through identification of ration shop customers, is unable to control per se. Furthermore, digital systems of allocation and monitoring - such as the two back-end modules of the Kerala PDS - may be constructed and utilized for this purpose. 
Two relevant cases here are those of Chhattisgarh and Karnataka, whose state-level PDS programmes have been informed by a holistic vision of ICT-based monitoring. Chhattisgarh, which is widely cited as a case of well-designed PDS reform, is enabling a tracking mechanism based on GIS devices, which allow to track the route of PDS goods from their origin at the FCI to their destination. In Karnataka, a front-end system (constituted by biometric weighing-cum-point of sale machines installed in the ration shops) is integrated with a back-end one, which automatizes financial and stock accounting through a software programme accessed by the AWDs. In both cases, technology is designed to track the supply chain in its entirety, with a view of preventing leakage at all the levels at which it may happen.

This lesson, elaborated with respect to the PDS, can be extended to the reasoning on computerization of social safety nets at large. Most anti-poverty schemes indeed consist of several layers of accountability, and/or are implemented through different phases: there may be, for technology designers, the temptation of limiting computerization to the user interface, and downplaying it in the rest of the programme. In the case of the Kerala PDS, intensive tracking of transactions in the ration shops is matched by sensibly lower investment on the monitoring of earlier phases: and this, while transforming the dynamics of the encounter between the programme and its recipients, does not help pursuing the core objective of digitalization, in terms of attacking diversion in the scheme as a whole. This is deeply illustrative of how, when having to do with a multi-layered programme, holistic monitoring (as opposed to sole digitalization of user interface) is important in creating the conditions for long-term, sustainable results.

The second lesson drawn from the study is that technology, from a normative point of view, could be used to carry an even more specific political agenda, to put ration dealers in the position of earning sustainable livelihoods without diversion. For example, ICTs can be instrumental in managing the transition to a system based on higher commissions, in which ration dealers get more substantial earnings on each purchase of PDS goods - and are, ideally, allowed to sell commodities beyond the anti-poverty system, therefore expanding their customer base. The key point here is that technology 
would play, once again, a role of support to political choices: what is needed, for the problem to be addressed, is practical commitment of state governments to include the objective of ration shop viability in their agenda. Governments need, in other words, to design systems in which ration dealers are not induced to use diversion as a route to sustainability.

While, as noted above, cases of holisting monitoring of PDS are found across India, very limited evidence exists on states using technology to reduce the incentive to diversion. In public discourse, ICTs are being increasingly constructed as a potential means for moving from PDS to cash transfers a system in which households, rather than receiving food rations, would be entitled to either food coupons, or pre-determined amounts of cash to use towards purchases of food. While the desirability or not of such move (and of the consequences it would entail) is beyond the focus of this paper, I do remark, here, that a shift to cash transfers would factually remove the need for ration shops: citizens would, instead, get their purchases from licensed grocery stores, and use their coupons to buy commodities (or, in the case of direct transfers, use the received cash for their best convenience). The consequence of this move would therefore be, in its essence, that of substantially dismantling the PDS as it currently works: this intention differs profoundly from the lesson suggested here, which points in the direction of strengthening the existing PDS in order to remove incentives to diversion. ${ }^{27}$

This suggests another core principle for computerization of social safety nets: if ICTs are to be used to improve existing social schemes, they should address the root causes of the problems into place. The vision of technology as a carrier of food security policies, as designed in the Kerala PDS, has high potential for programme improvement: however, its ambitious scope is to be combined with a focus on the issues that perpetuate diversion, such as the chronic unviability of ration shops and the corrupted practices that stem from it. Most social safety programmes are there to address symptomatic issues, in a pletora of domains of social development: when computerization is designed for them, designers need to firstly trace the origins of these problems, and devise a coherent strategy to combat their very roots. This seems to be the best way to build durable solutions, whose capability of addressing core problems makes them sustainable in the long run. 
The recent approval of the NFSA, determining a return to quasi-universality of the PDS, makes an important step in the direction of increasing viability of ration shops. By reducing the difference in subsidy according to poverty status, this measure aims to expand the customer base of the FPS, and to diminish, in parallel, the amount of gains from diversion. The modifications required by the NFSA will channel computerization into precise directions, for states that are engaging in this process just now: technology will have to be, at least on paper, the enabler of a system that combats market diversion at its very origin. In this crucial historical phase, I hope that the findings collected in this paper may be of use to Indian state governments, for the link between e-governance and development to be embodied in the implementation of the food security system.

\section{References}

Ahluwalia, D. (1993). Public distribution of food in India: coverage, targeting and leakages. Food Policy, 18(1), 33-54.

Bhatia, D., Bhatnagar, S. C., \& Tominaga, J. (2009). How do manual and e-government services compare? Experiences from India. Information and Communications for Development 2009: Extending Reach and Increasing Impact, 67-82.

Bhatnagar, S. (2004). E-government: From vision to implementation - a practical guide with case studies. New Delhi: Sage.

Bovens, M., \& Zouridis, S. (2002). From street-level to system-level bureaucracies: How information and communication technology is transforming administrative discretion and constitutional control. Public Administration Review, 62(2), 174-184. 
Braun, J.V., Ruel, M., \& Gulati, A. (2008). Accelerating progress toward reducing child malnutrition in India - A concept for action. Washington DC: International Food Policy Research Institute (IFPRI).

Bussell, J. (2012). Corruption and reform in India: Public services in a digital age. Cambridge: Cambridge University Press.

Chatterjee, P. (1986). Nationalist thought and the colonial world: A derivative discourse. London: Zed Books.

Corbridge, S., Williams, G., Srivastava, M., \& Véron, R. (2005). Seeing the state: Governance and governmentality in India. Cambridge: Cambridge University Press.

Corbridge, S., \& Harriss, J. (2000). Reinventing India: liberalization, Hindu nationalism and popular democracy. Cambridge: Polity Press.

Cordella, A., \& Iannacci, F. (2010). Information systems in the public sector: The e-Government enactment framework. The Journal of Strategic Information Systems, 19(1), 52-66.

Deaton, A., \& Drèze, J. (2002). Poverty and inequality in India: A re-examination. Economic \& Political Weekly, 37(36), 3729-3748.

Drèze, J., \& Khera, R. (2013). Rural poverty and the Public Distribution System. Working paper no. 235, Centre for Development Economics, Delhi School of Economics.

Drèze, J., \& Khera, R. (2010). The BPL census and a possible alternative. Economic \& Political Weekly, 45(9), 54-63.

George, P.S. (1979). Public distribution of foodgrains in Kerala: Income distribution implications and effectiveness. Washington DC: International Food Policy Research Institute (IFPRI). 
Government of India (2010). Planning commission report, mid-term appraisal on Eleventh Five-Year Plan. Retrieved from <www.planningcommission.nic.in>.

Heeks, R. (2001). Understanding e-governance for development. The University of Manchester, Institute for Development, Policy and Management Information, Systems, Technology and Government: Working Papers Series, Number 11/2001.

Heller, P. (1995). From class struggle to class compromise: Redistribution and growth in a South Indian state. The Journal of Development Studies, 31(5), 645-672.

Himanshu (2013). PDS: A story of changing states. Live Mint, $7^{\text {th }}$ August 2013.

Jha, R., Gaiha, R., Pandey, M.K., \& Kaicker, N. (2013). Food subsidy, income transfer and the poor: A comparative analysis of the Public Distribution System in India's states. Journal of Policy Modeling, 35, 88-908.

Justice Wadhwa Committee on Public Distribution System (2010). Report on the state of Kerala. New Delhi, Central Vigilance Committee on the Public Distribution System. Retrieved from $<$ www.pdscvc.nic.in>.

Khera, R. (2011a). India's public distribution system: Utilisation and impact. Journal of Development Studies, 47(7), 1038-1060.

Khera, R. (2011b). Trends in diversion of grain from the Public Distribution System. Economic \& Political Weekly, 46(21), 106-14. 
Kochar, A. (2005). Can targeted food programs improve nutrition? An empirical analysis of India’s Public Distribution System. Economic Development and Cultural Change, 54(1), 203-235.

Krishnakumar, R. (2000). Public Distribution System: A system in peril. Frontline, 17(19), 16-29.

Kumar, S.K. (1979). Impact of subsidized rice on food consumption and nutrition in Kerala. Washington DC: International Food Policy Research Institute (IFPRI).

Madon, S. (2009). E-governance for development: A focus on rural India. London: Palgrave Macmillan.

Madon, S. (2005). Governance lessons from the experience of telecentres in Kerala. European Journal of Information Systems, 14(4), 401-416.

Mooij, J. (1998). Food policy and politics: The political economy of the Public Distribution System in India. The Journal of Peasant Studies, 25(2), 77-101.

Nair, E. C. (2000). Interview: “Centre should change its policy”. Frontline, 17(19), 16-29.

National Informatics Centre - NIC Kerala (2010). Targeted, Efficient and Transparent Rationing and

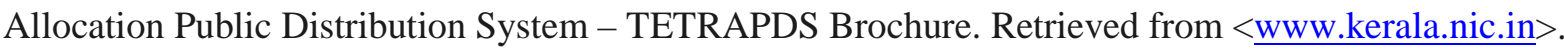

Parikh, K. S. (1994). Who gets how much from PDS: How effectively does it reach the poor. Sarvekshana, 17(3), 1-3.

Pathak, P.K., \& Singh, A. (2011). Trends in malnutrition among children in India: growing inequalities across different economic groups. Social Science \& Medicine, 73(4), 576-585. 
Pritchard, B., Rammohan, A., Sekher, M., Parasuraman, S. \& Choithani, C. (2013). Feeding India: Livelihoods, entitlements and capabilities. London: Earthscan.

Radhakrishna, R., \& Subbarao, K. 1997. India's Public Distribution System: A national and international perspective. Washington DC: World Bank.

Ramakumar, R. (2010). The unique ID project in India: A skeptical note. In Kumar, A., and Zhang, D. (Eds.), Ethics and Policy of Biometrics, Berlin: Springer.

Riessman, C.K. (2008). Narrative methods for the human sciences. Thousand Oaks: Sage.

Sen, A., \& Himanshu (2004). Poverty and inequality in India II: Widening disparities during the 1990s. Economic and Political Weekly, 39(39), 4361-4375.

Sen, A., \& Himanshu (2011). Why not a universal food security legislation?. Economic \& Political Weekly, 46(12), 38-47.

Suchitra, M. 2004. Undermining a fine Public Distribution System in Kerala. Retrieved from $<$ www.indiatogether.org $>$.

Suryanarayana, M.H. (2001). Economic reform versus food security: Kerala’s Gordian knot. Journal of International Development, 13(2), 239-253.

Svedberg, P. (2012). Reforming or replacing the Public Distribution System with cash transfers?. Economic \& Political Weekly, 47(7), 53-62. 
Swaminathan, M. (2010). The new poverty line: A methodology deeply flawed. Indian Journal of Human Development, 4(1), 121-125.

Swaminathan, M. (2008). Programmes to protect the hungry: Lessons from India. Working Paper no.70 at United Nations Department for Economics and Social Affairs.

Swaminathan, M. (2002). Excluding the needy: The public provisioning of food in India. Social Scientist, 30(3): 34-58.

UIDAI, Unique Identification Authority of India Planning Commission (2009). UID and PDS System. UIDAI Working Paper, retrieved from < www.uidai.gov.in>.

Umali-Deininger, D. L., \& Deininger, K. (2001). Towards greater food security for India’s poor: Balancing government intervention and private competition. Agricultural Economies, 25(2-3), 321335.

Véron, R. (2001). The "new" Kerala model: Lessons for sustainable development. World Development, 29(4), 601-617.

Yin, R.K. (2009). Case study research: Design and methods (Vol. 5). London: Sage.

\section{Endnotes}

\footnotetext{
${ }^{1}$ In fact, the extent to which poverty has declined in the 1990s is still a matter of controversy. Deaton and Drèze (2002), after reassessment of data from the $55^{\text {th }}$ round of the National Sample Survey (NSS), sustain that poverty reduction, in that decade, has proceeded similarly to earlier trends. This point is contested by Sen and Himanshu (2004), whose interpretation points to a sharp increase in inequality, which resulted in severe deterioration of nationwide poverty reduction.
} 


\footnotetext{
${ }^{2}$ When looking at child malnutrition specifically, India ranks 117 among 119 countries (Braun, Ruel \& Gulati, 2008, cited in Pathak \& Singh, 2011).
}

${ }^{3}$ Total expenditure in food subsidies amounted to USD 12.4 billion, or around 1\% of the national GDP in 2009 (Jha, Gaiha, Pandey, \& Kaicker, 2013).

${ }^{4}$ In some states (e.g. Karnataka), the number of members registered in each household also plays a part in the determination of theoretical requirement for each ration dealer.

${ }^{5}$ Targeting has been adopted in all states except for Tamil Nadu, where the PDS has remained universal.

${ }^{6}$ According to Swaminathan's data (2008, pp.16-19), the consequences of exclusion errors are particularly hard on vulnerable groups. Categories affected by high exclusion rates include agricultural labor households (52.1\%), scheduled caste (60.7\%), and lower-income groups at the all-India level.

${ }^{7}$ Diversion from the PDS is measured also by Khera (2011a), who compares offtake data from the Ministry of Food and Consumer Affairs and consumption data from the $61^{\text {st }}$ round of the NSS. Her estimates point to a rate of diversion that amounts to two fifths of the official PDS offtake.

${ }^{8}$ In fact, the NFSA does not formally restructure the PDS according to a criterion of universality. Substantially, though, it expands the coverage of the subsidy system in an unprecedented way - under the Act, subsidized foodgrains will be granted to around two thirds of India's population. This is why the adoption of the NFSA is referred to as a move towards universality (e.g. Sen \& Himanshu 2011).

${ }^{9}$ State-level data from the Justice Wadhwa Committee have been adjusted as a result of the policy changes operated in 2011, as a result of which subsidies to the BPL and AAY have been increased.

${ }^{10}$ To be sure, when computerization of the PDS was started, a well-rooted and comprehensive e-governance infrastructure was already present. Historically, Kerala’s tradition of social development has been matched by a 
model of e-governance aimed at democratizing access and its benefits. This is why access is based on Akshaya telecentres, the Internet kiosks planned to be distributed across the whole state (Madon, 2005).

${ }^{11}$ The ration card in Kerala is a household-based document. Modifications to existing cards are therefore required every time a household alters its composition (new households formed as a result of marriage, addition/deletion of members, etc.) or relocates (in which case a surrender certificate needs to be released).

${ }^{12}$ In case of suspension of a ration dealer's licence due to irregularities found by rationing inspectors, the system allows registration of customers of that shop to another FPS, determined on the basis of geographical proximity.

${ }^{13}$ Interview, NIC Kerala, $7^{\text {th }}$ November 2011.

${ }^{14}$ Interviews, staff at Akshaya centres, Malappuram district, $21^{\text {st }}$ August 2012.

${ }^{15}$ Interviews, Taluk Supply Offices, Trivandrum and Malappuram districts, $18^{\text {th }}-19^{\text {th }}$ June and $20-28^{\text {th }}$ August 2012.

${ }^{16}$ Interviews, Food and Civil Supplies Department, Government of Kerala, $18^{\text {th }}$ November 2011 and $20^{\text {th }}$ June 2012.

${ }^{17}$ Interview, Kerala State Information Technology Mission, $4^{\text {th }}$ August 2012.

${ }^{18}$ Interview, Kerala State Information Technology Mission, 4 ${ }^{\text {th }}$ August 2012.

${ }^{19}$ Interview, NIC Kerala, $22^{\text {nd }}$ June 2012.

${ }^{20}$ Interview, PDS user - Kollam district, $11^{\text {th }}$ August 2012.

${ }^{21}$ Interview, PDS user - Malappuram district, 20 ${ }^{\text {th }}$ August 2012. 
${ }^{22}$ On this, Ramakumar (2011) notes that: "in the operation of the PDS, there are two major sources of leakage. First, there are leakages after foodgrains leave the godown and before they reach the fair price shop. Secondly, there are leakages between the FPS and the customers. Any observer of the PDS knows that the major proportion of leakages belong to the former category, and the latter accounts for only a small proportion”.

${ }^{23}$ In fact, according to the estimates in point, Kerala's rates of diversion from the PDS are among the lowest in all India. This is ascribed to the high levels of public vigil and community monitoring that feature in the state. However, comparison with the rest of India should not lead to downplay the consequences of diversion, which still remains the main cause preventing beneficiaries from access to subsidized goods.

${ }^{24}$ Interviews, PDS users - Trivandrum, $8^{\text {th }}$ August 2012.

${ }^{25}$ Interviews, Taluk Supply Officer - Kollam district, $28^{\text {th }}$ August 2012.

${ }^{26}$ As of the Justice Wadhwa Commission Report on the Public Distribution System (2010, p. 19), "it is no secret that an FPS dealer cannot honestly earn enough to sustain himself and his family. To avoid running losses, he indulges in black marketing.”

${ }^{27}$ An extensive discussion on the consequences of a shift to cash transfers, and on the roles that technology may potentially play in such shift, is provided in Pritchard, Rammohan, Sekher, Parasuraman, \& Choithani (2013, pp. 129-151). 